\title{
Effect of Multilayered Structure on Properties of Ti/TiN Coating
}

\author{
Wang Yanfeng ${ }^{1,2}$, Li Zhengxian², Wang Haonan², Du Jihong ${ }^{2}$, Zhang Changwei ${ }^{2}$ \\ ${ }^{1}$ Xi'an University of Architecture \& Technology, Xi'an 710055, China; ${ }^{2}$ Northwest Institute for Nonferrous Metal Research, Xi'an 710016, China
}

\begin{abstract}
Metal nitride hard coatings, such as TiN and TiAlN are widely used to protect materials because of their higher hardness and wear properties. However, these coatings always contain a high degree of internal stress which could arouse adhesion problems. It is hard to synthesize monolayer TiN or TiAlN coatings thicker than $10 \mu \mathrm{m}$ by PVD (physical vapor deposition). The multilayer composite structure, offering efficient means of controlling residual stress, is a successful way to synthesize thicker hard coatings. In the present study, a series of multilayer composite Ti/TiN coatings with different composite periods were synthesized by plasma enhanced ion plating and the effects of multilayered structure mechanical properties of the coating was studied. The result shows that the mechanical properties of the coating are strengthened with increasing the periods of composite Ti/TiN layer. The micro hardness (HV0.25) can reach to about $27500 \mathrm{MPa}$ and better toughness and higher thickness ( $>50 \mu \mathrm{m}$ ) are obtained. The toughness of the coating is almost directly proportional to hardness. Meanwhile, the tribological performance of the coating is improved with a lower dry friction coefficient (about 0.35 ) and higher wear resistance by alternating 48 periods of Ti/TiN layer. However, the bonding strength of the coating is weakened with further increasing the period of Ti/TiN layer due to the weak interface of coating and substrate.
\end{abstract}

Key words: Ti/TiN coating; multilayered structure; micro hardness; tribological performance; toughness

Metal nitride hard coatings, such as TiN, TiAlN, have been widely used to protect the component because of their higher hardness, better tribological properties and oxidation resistance ${ }^{[1-6]}$. However, the applicability of these hard coatings has been constrained by limitations of the coating thickness. Hard coatings, synthesized by PVD technology always contains high degree residual stress owing to lattice distortion and thermal mismatch effects which is bad for ceramic coating's fatigue life, bonding strength and so on ${ }^{[7,8]}$. Therefore, it is hard to synthesized monolayer PVD hard coating thicker than $10 \mu \mathrm{m}$ without adhesion problems. Many ways were proposed to minimize or eliminate that residual stress. Researchers ${ }^{[9,10]}$ have revealed that ductile titanium interlayer in multilayer Ti/TiN coatings could accommodate the TiN internal stresses and was necessary to the residual stresses relaxation. Following this guideline, thick hybrid metal/ceramic coatings were produced by $\mathrm{Ti}$ interlayer accommodating the TiN residual stress ${ }^{[1-14]}$. According to their researches, a favorable residual stress gradient could be formed by that multilayered structure. Besides, by adjusting Ti interlayer's thickness, a significant improvement of mechanical properties such as wear resistance, toughness and adhesion was achieved. These improvements were related to some (or a combination) of the following mechanisms: crack deflection duo to weak interface, crack-tip shielding by plastic deformation in combination with strong interfaces, crack deflection due to differences in the elastic modulus of the individual layer materials, compared to monolayer TiN coating ${ }^{[15-18]}$.

Although a lot of research pointed out that the multilayered structure was an effective way to improve PVD hard coating's thickness, and thick hard coatings have been synthesized with better performance, any deep study of the influence of periods of Ti/TiN layer on their mechanical properties has not been carried out. In the present research, a series of multilayered thick Ti/TiN hard coating with various periods was synthesized and the effect of periods on coating's hardness,

Received date: May 20, 2016

Foundation item: National International Science and Technology Corporation (2014DFR50450); National Basic Research Program of China (2012CB625100)

Corresponding author: Wang Yanfeng, Senior Engineer, Northwest Institute for Nonferrous Metal Research, Xi'an 710016, P. R. China, Tel: 0086-29-86231077,

E-mail: yfwang420@163.com

Copyright $($ C 2017, Northwest Institute for Nonferrous Metal Research. Published by Elsevier BV. All rights reserved. 
toughness, adhesion and tribological performance was studied in detail.

\section{Experiment}

Multilayered $\mathrm{Ti} / \mathrm{TiN}$ hard coatings with various periods were deposited onto TC4 alloys and Si (100) substrates by plasma-enhanced ion plating system using high purity $\mathrm{Ti}$ symmetrical targets at $300{ }^{\circ} \mathrm{C}$. Technical principle and advantage of the plasma-enhanced effect has been shown in our earlier publication ${ }^{[19]}$.

The TC4 and Si (100) samples were polished to mirror, washed in distilled water, dried in warm air and fixed on a turntable between the targets and the target-to-substrate distance was fixed at $50 \mathrm{~mm}$ as usual. Prior to deposition, the system was evacuated to a vacuum pressure of $1 \times 10^{-4} \mathrm{~Pa}$ and $\mathrm{Ti}$ ion cleaning on samples at bias voltage of $-1100 \mathrm{~V}$ was carried out to eliminate contamination and improve adhesion. Then a series of multilayered $\mathrm{Ti} / \mathrm{TiN}$ coatings with various periods were deposited on the substrates at bias voltage of $-100 \mathrm{~V}$. In this study, the thickness of Ti interlayer was set at $100 \mathrm{~nm}$ and that of TiN was set at $500 \mathrm{~nm}$. At the same time, a monolayer TiN was deposited in order to make comparison.

A scanning electron microscopy operated at $20 \mathrm{kV}$ (JSM-6700F, SEM) was employed to study the coatings' cross-sectional morphology and thickness. The hardness was evaluated by micro indention measurement (MH-5 digital Vickers micro hardness tester) at load of $25 \mathrm{~g}$ and dwell time of $10 \mathrm{~s}$. The adhesion was quantitatively evaluated using WS-97 automatism loading scratch instrument at a scratch speed of $40 \mathrm{~N} / \mathrm{min}$. And the tribological performance was characterized by HT-500 ball-on-disk abrasion apparatus. The test was carried out at room temperature and lasted about 40 min with $\mathrm{Si}_{3} \mathrm{~N}_{4}$ ball (6 $\mathrm{mm}$ in diameter) as the frictional pair, extra load of $5 \mathrm{~N}$ and disk speed of $560 \mathrm{r} / \mathrm{min}$.

According to Lawn, Evans and Marshall ${ }^{[20]}$, the toughness of the coating bears the following relationship with the length of cracks and applied load using micro indention measurements.

$$
K_{\mathrm{IC}}=\delta(E / H)^{1 / 2}\left(P / C^{3 / 2}\right)
$$

Where $P$ is the applied indentation load, $E$ and $H$ are the elastic modulus and hardness of the film, respectively. $C$ is the length of cracks, and $\delta$ is an empirical constant which depends on the geometry of the indenter ${ }^{[21,22]}$.

\section{Results and Discussion}

\subsection{Cross-sectional morphologies of $\mathrm{Ti} / \mathrm{TiN}$ coatings}

A typical columnar structure with micro cracks and through-coating pinholes can be seen clearly from Fig.1a. That structure often has a high degree interfacial residual stress which is bad for thick coating synthesis. With ductile Ti interlayer's accommodation, a multilayered structure can be formed which is necessary to the residual stress relaxation. As shown in Fig.1b, 1c and 1d, 6 periods, 24 periods and about 150 periods of multilayer composite $\mathrm{Ti} / \mathrm{TiN}$ coatings were deposited and the maximum thickness could reach to over 100 $\mu \mathrm{m}$ without adhesion problems. It is confirmed that hard PVD coatings with high thickness can be achieved by adopting the multilayered composite structure.

The high thickness of multilayered composite Ti/TiN coating can be attributed to the modulated function of Ti interlayer. Firstly, the re-nucleation of the TiN phase is promoted by Ti interlayer and so the growth of TiN columnar crystals is restrained. As a result, the defects in the columnar structure

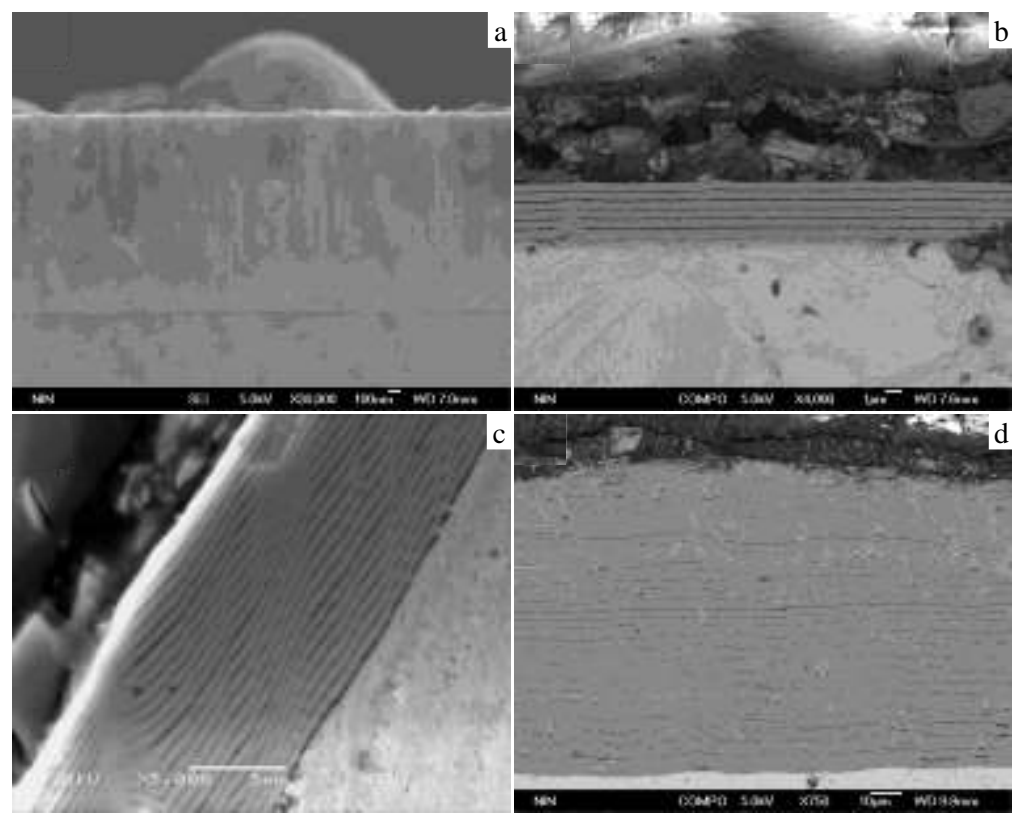

Fig.1 Cross-sectional morphologies of Ti/TiN coatings with different composite structures: (a) single TiN coating, (b) Ti/TiN coating with 6 periods, (c) Ti/TiN coating with 24 periods, and (d) Ti/TiN coating with 150 periods 
are also reduced, leading to a more compact microstructure and less accumulation of residual stress. Secondly, the Ti interlayer could promote the release of residual stress. Through accommodation function of $\mathrm{Ti}$ ductile layer, residual stress aroused during TiN coating deposition could be dispersed in each Ti/TiN modulated cell and restricted in a very low level ${ }^{[15]}$. And then a symmetrical residual stress grads field is formed which is good for the coatings' bonding strength.

\subsection{Effect of multilayered composite structure on coating's bonding strength}

Due to the ductile $\mathrm{Ti}$ interlayer, the multilayered $\mathrm{Ti} / \mathrm{TiN}$ coatings have a lower level of residual stress, and the multilayered composite structure would induce a positive effect to the coating's mechanical properties. In this study, multilayered Ti/TiN coatings' hardness and bonding strength were quantitatively evaluated by means of scratch and micro indentation, and the results are as following.

Because of poor plastic property, hard ceramic coatings would be cracked and eventually fractured at a critical scratch load. The critical load is considered as the coating's quantitative bonding strength. As shown in Fig.2, the load at the inflexion of curve represents the critical load. The bonding strength of monolayer TiN coating of about $5 \mu \mathrm{m}$ in thickness is only about $25 \mathrm{~N}$, and that of 48 periods of Ti/TiN coatings is improved to more than $70 \mathrm{~N}$ which indicates that multilayered composite structure is beneficial for the bonding strength. The relation between bonding strength and periods of Ti/TiN layer is shown in Fig.3. Unexpectedly, with further increasing the periods of Ti/TiN, the value of bonding strength shows a sharp decrease. The coating with 180 periods has the lowest bonding strength, about $32 \mathrm{~N}$ which is still higher than that of monolayer TiN coating. Those results reveal that the multilayered composite structure with proper amount of composite layer could enhance the bonding strength remarkably, but the more, the worse. In this study, the highest bonding strength is about $70 \mathrm{~N}$ with 48 periods of Ti/TiN and the thickness could reach to about $30 \mu \mathrm{m}$.

The main factors that influence coating's bonding strength are the residual stress in the coating and the interface

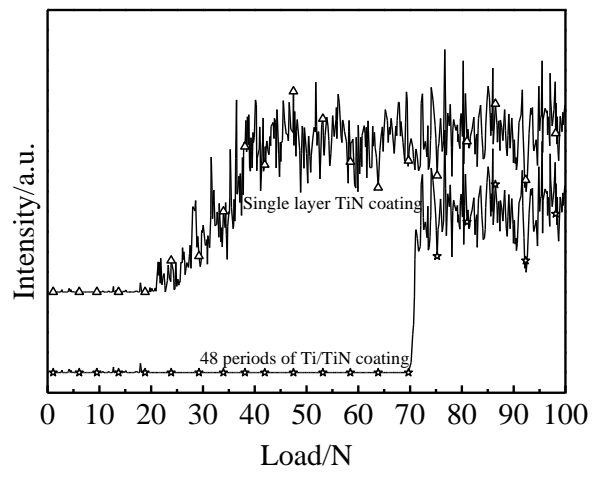

Fig.2 Bonding strength of single TiN and 48 periods of Ti/TiN multilayered coatings

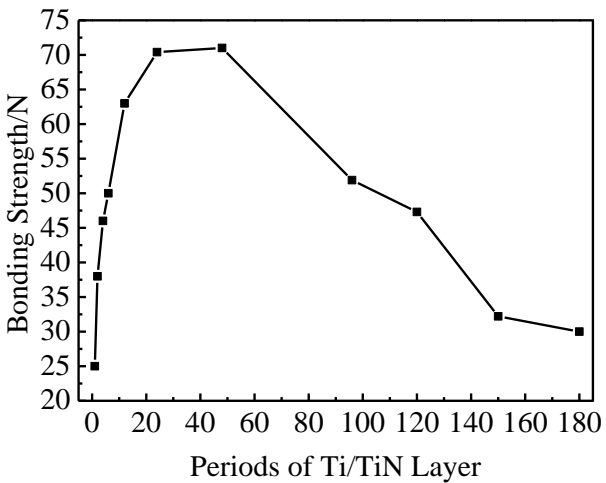

Fig.3 Effect of periods of Ti/TiN layer on coatings' bonding strength

between coating and substrate. For the monolayer TiN coating, a micro crack would be formed firstly at contact area under an extra load, and then the residual stress, mostly of the tensile stress would be released through that crack. Along with increasing the scratch load, more energy is applied to the crack, accelerating its propagation. Then the coating would be fractured when the tensile stress exceeds the cohesion of coating and substrate. But that residual stress could be dispersed by multilayered structure and is reduced to a lower level in each Ti/TiN period; a stress gradient is also formed which is good for relaxation of stress. The crack-tip is shielded by plastic deformation of the ductile Ti interlayer and the stress gradient field, avoiding expansion of the crack. So the bonding strength is improved. However, the positive effect would be eliminated gradually when the composite Ti/TiN layers exceed a limit period. In this study, the limit amount is about 48 periods. When the composite layers exceed this value, the bonding strength decreases clearly (according to Fig.3). The phenomenon could be explained by the negative effect of accumulated residual stress in each Ti/TiN period. When the residual stress exceeds the endurable limit of multilayered structure, the weak interface could not sustain the whole coatings anymore and results in desquamation and failure of the coating.

\subsection{Effect of multilayered composite structure on} coating's hardness and indentation toughness

Contrarily, effect of the multilayered composite structure on coating's hardness is positive. The coating's hardness is strengthened along with increase of the composite periods, as shown in Fig.4. The highest hardness $\left(\mathrm{HV}_{0.25}\right)$ is about 27500 $\mathrm{MPa}$, and does not change obviously any more when the periods are increased further. In addition, the toughness of the coating is improved synchronously. Fig.5 shows the cracks in the coatings on $\mathrm{Si}$ (100) with different $\mathrm{Ti} / \mathrm{TiN}$ periods at different extra load. The radial crack could be seen clearly from the monolayer TiN coating at the lowest measured load, about $2 \mathrm{~N}$ as shown in Fig.5a, but the crack is shortened when the measured load increases by adopting the ductile $\mathrm{Ti}$ 


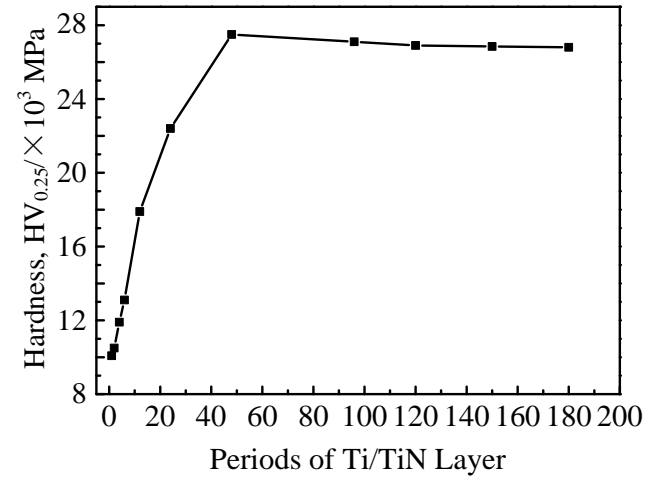

Fig.4 Effect of periods of Ti/TiN layer on coating's hardness

interlayer, as shown in Fig.5b and 5c, meaning that the toughness is strengthened. Comparing the length of cracks and measured load, it could be inferred that, a multilayered Ti/TiN coating with 96 periods at measured load of $10 \mathrm{~N}$ has the best toughness. According to Eq. (1), a quantitative toughness evaluation could be calculated. The elastic modulus of multilayered Ti/TiN coating with 12 periods is about $200 \mathrm{GPa}$ by means of nanoindentation. And for simplicity, it could be considered that all the Ti/TiN coatings in this study have the same elastic modulus due to their same microstructure. Fig.6 displays the relationship between the toughness and Ti/TiN periods, indicating that multilayered composite structure has a positive effect on its toughness, almost proportional to hardness. But after the periods of $\mathrm{Ti} / \mathrm{TiN}$ reach to 48 , that positive effect is weakened and the toughness show a constant current, meaning that coating's toughness is converged to the true value. In the present experiment, the highest $\mathrm{Ti} / \mathrm{TiN}$ coating toughness could reach to about $4.29 \mathrm{MPa} / \mathrm{m}^{1 / 2}$.

The improvement of hardness and toughness could be attributed to the multilayered structure. The multilayered composite structure formed by alternating the ductile $\mathrm{Ti}$ and hard TiN layer could absorb the impact action of extra load and a higher surface elastic deformation resistance is gained, so the hardness could be improved obviously. And also a shear strain zone could be also formed by the multilayer composite structure, resulting in a bended but not fractured brittle coating under the normal load. Simultaneously, the micro crack would be surrounded and deflected by the higher intensity interface because of elastic deformation, so the expansion of the crack is restrained and the fracture strength is improved. As a result, the multilayer composite Ti/TiN coating possesses higher surface hardness while is toughened by the structure.

\subsection{Effect of multilayered composite structure on tribolo- gical properties}

Tribological properties of hard coatings are one of the most important factors to evaluate their service performance. The tribological performance of monolayer TiN layer and

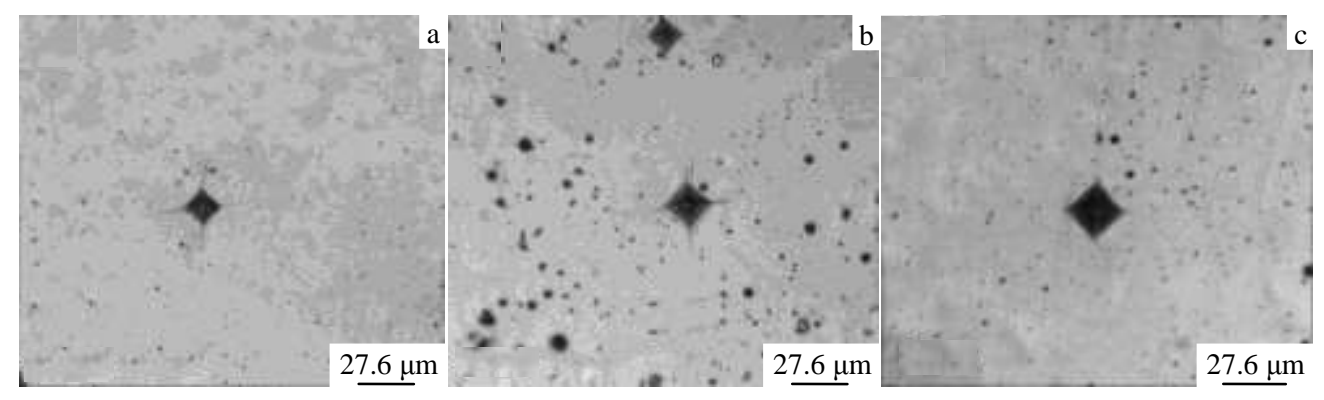

Fig.5 Micrographs of indents on varied TiN coatings deposited on Si(100) substrates: (a) single TiN coating at load of 2 N,

(b) 6 periods of Ti/TiN coating at load of $3 \mathrm{~N}$, and (c) 96 periods of Ti/TiN coating at load of $10 \mathrm{~N}$

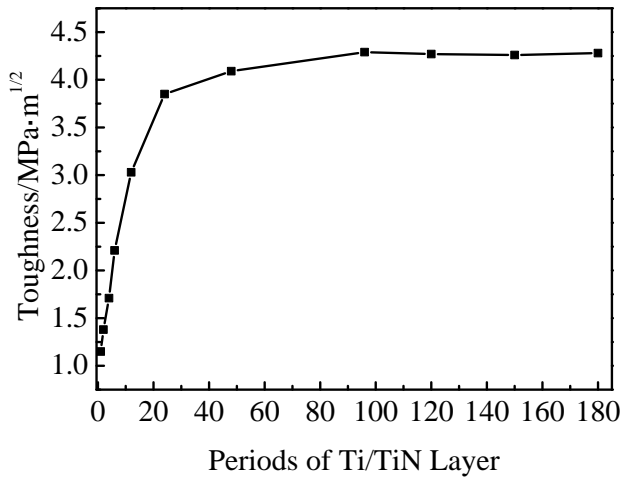

Fig.6 Relationship between toughness and periods of Ti/TiN layer multilayered composite Ti/TiN coating (with 48 periods of layer) is shown in Fig.7. The substrate's tribological performance is improved remarkably. The friction coefficient is reduced from 0.9 to about 0.45 by the monolayer TiN coating, but the substrate coated 48 periods of Ti/TiN coating has the lowest friction coefficient, only about 0.35 . It is believed that the multilayered composite structure could improve the tribological performance. By means of SEM, the wear track of sample coated multilayered composite Ti/TiN coating's morphologies was examined in detail. As shown in Fig.8, a very good wearing state is got from the multilayered composite Ti/TiN coating and any wear debris could not be seen from the wear track which indicates the coated substrate has a better tribological performance. And from the magnified 


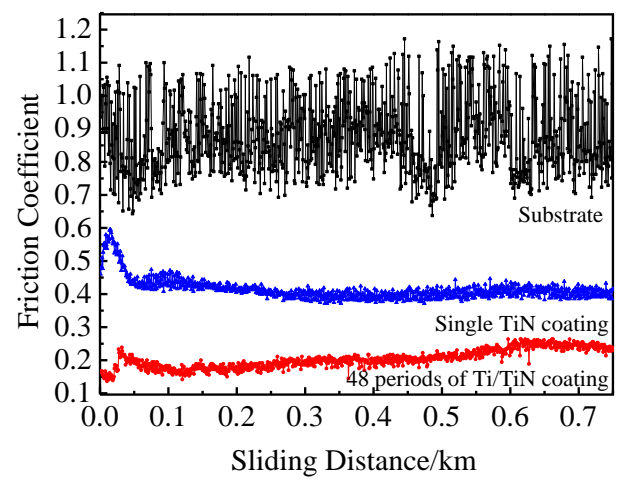

Fig.7 Comparison of friction coefficients determined from the substrate, single TiN and 48 periods of Ti/TiN coating at room temperature

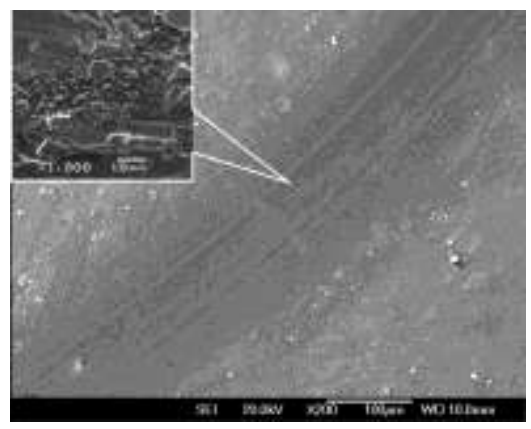

Fig.8 Morphologies of the wear track of 48 periods of Ti/TiN coating

local area of the wear track, a gradual grads abrasion manner could be seen clearly. In other words, after the former TiN layer is worn out, the latter Ti/TiN layer would continue to wear.

Currently, whether the coating has good tribological performance is determined by the coating's microstructure and mechanical properties. Firstly, the coating with higher hardness would have better wear resistance. In this study, the TC4 substrate is strengthened by the multilayered composite Ti/TiN coating, resulting in a hardened surface. The hardened surface is expected to have a smaller contact area during the friction process, leading to a smaller frictional force on the coating, which is good for tribological performance ${ }^{[23]}$. Secondly, the toughened Ti/TiN coating has a better plastic deformation and denser structure with less defects such as micro cracks and pinholes, comparing with monolayer TiN coating, as shown in Fig.1. So it can absorb the impulse action of the load by plastic bend deformation and still keep integrity after friction, as shown in Fig.8. Due to these positive effects, the crack initiation and propagation is restrained and less wear debris is formed during the friction, which is good for the tribological performance. Thirdly, according to the research of Yuanyuan Cheng et $\mathrm{al}^{[24]}$, the soft $\mathrm{Ti}$ interlayer had a lower shear strength and acted as a solid lubricant during wear testing, corresponding to the decrease in the friction coefficient of the multilayered Ti/TiN coating.

\section{Conclusions}

1) A highly thick multilayered composite Ti/TiN coating is deposited on TC4 alloys and the bonding strength and hardness of the coating are strengthened by alternating soft $\mathrm{Ti}$ and hard TiN layer.

2) The multilayered composite structure, especially the soft Ti interlayer is very important.

3) The inner residual stress is dispersed in each Ti/TiN layer unit and a symmetrical residual stress grads field is formed which could improve the composite mechanical properties.

4) The hardness of the coating is improved with higher toughness.

5) The denser, harder and tougher Ti/TiN coating shows a better tribological performance with higher wear resistance and lower friction coefficient.

\section{References}

1 Todt J, Pitonak R, Köpf A et al. Surface and Coatings Technology[J], 2014, 258: 1119

2 Azadi M, Sabour A Rouhaghdama, Ahangarani S et al. Surface and Coatings Technology[J], 2014, 245: 156

3 Wu Hua, You Shenshen, Jiang Ying. Rare Metal Materials and Engineering[J], 2016, 45(5): 1209 (in Chinese)

4 Zhao Shilu, Zhang Zhen, Zhang Jun et al. Rare Metal Materials and Engineering[J], 2016, 45(5): 1320 (in Chinese)

5 Wang Y F, Li Z X, Du J H et al. Applied Surface Science[J], 2011, 258(1): 456

6 Chen T, Xie Z W, Gong F et al. Applied Surface Science[J], 2014, 314: 735

7 Shum P W, Tam W C, Li K Y et al. Wear[J], 2004, 257(9-10): 1030

8 Teixeira V. Thin Solid Films[J], 2001, 392(2): 276

9 Leyland A, Matthews. Surface \& Coating Technology[J], 1994, 71: 19

10 Kim G S, Lee S Y, Hahn J H et al. Surface \& Coating Technology[J], 2003, 171(1-3): 83

11 Zhang Xiaoyu, Tan Jun. Surface Technology[J], 2015, 44(12): 80 (in Chinese)

12 Vogli E, Tillmann W, Selvadurai-Lassl U et al. Applied Surface Science[J], 2011, 257: 8550

13 Wei Yongqiang, Zong Xiaoya, Wu Zhongzhen et al. Surface and Coatings Technology[J], 2013, 229: 191

14 Alat Ece, Motta Arthur T, Comstock Robert J et al. Journal of Nuclear Materials[J], 2016, 478: 236

15 Ali R, Sebastiani M, Bemporad E. Materials and Design[J], 2015, 75: 47

16 Cheng Y H, Browne T, Heckerman B et al. Surface and Coatings Technology[J], 2010, 205: 146

17 Zhou D P, Hui Peng, Liu Zhu et al. Surface and Coatings Technology[J], 2014, 258: 102

18 Li Jianzhong, Zheng Hua, Sinkovits Theo et al. Applied Surface 
Science $[\mathrm{J}], 2015,355: 502$

19 Wang Y F, Li Z X, Du J H et al. Applied Surface Science[J], 2010, 257(1): 1

20 Lawn B R, Evans A G, Marshall D B. Journal of the American Ceramic Society[J], 1980, 63(9-10): 574

21 Bemporad E, Sebastiani M, Pecchio C et al. Surface and Coatings Technology [J], 2006, 201: 2155
22 Zhang S, Sun D, Fu Y Q et al. Surface and Coatings Technology [J], 2005, 198: 74

23 Wang Y F, Ma S L, Chu P. Surface Engineering[J], 2010, 26(8): 571

24 Cheng Yuanyuan, Pang Xiaolu, Gao Kewei et al. Thin Solid Films[J], 2014, 550: 428

\title{
多层结构对 Ti/TiN 涂层性能的影响
}

\author{
王彦峰 ${ }^{1,2}$, 李争显 ${ }^{2}$, 王浩楠 ${ }^{2}$, 杜继红 ${ }^{2}$, 张长伟 ${ }^{2}$ \\ (1. 西安建筑科技大学, 陕西 西安 710055) \\ (2. 西北有色金属研究院，陕西 西安 710016)
}

\begin{abstract}
摘 要: 以 $\mathrm{TiN} 、 \mathrm{TiAlN}$ 为主的过渡族金属氮化物硬质涂层以其较高的表面硬度、良好的耐磨以及抗高温氧化性能, 被广泛应用于材料 表面防护涂层。然而, 涂层内部积聚的高内应力却容易引发涂层与基体的结合力问题。利用 PVD 技术很难在材料表面制备出厚度超过 $10 \mu \mathrm{m}$ 的 TiN 或 TiAlN 涂层。多层复合结构能够有效控制涂层中的应力分布，从而使得其成为获得较厚硬质涂层的一种有效方法。本工 作在 TC4 合金以及 $\mathrm{Si}$ （100）基体上利用等离子增强离子镀技术制备了具有不同复合层数的多层 $\mathrm{Ti} / \mathrm{TiN}$ 涂层, 并研究了复合层数对涂层 力学性能的影响。结果表明, 随着复合层数的增加, 涂层的各项力学性能得到了显著强化。涂层的显微硬度 $\mathrm{HV}_{0.25}$ 高达 $27500 \mathrm{MPa}$, 厚 度大于 $50 \mu \mathrm{m}$, 且具有较好的韧性。涂层的㓞性与显微硬度成正比例关系。同时, 48 层复合结构的 Ti/TiN 涂层具有低于 0.35 的摩擦系 数以及最佳的抗磨损性能。然而, 随着复合层数的进一步增加, 涂层与基体的界面结合强度显著弱化。
\end{abstract}

关键词：Ti/TiN 涂层；多层结构；显微硬度；摩擦性能；㓞性

作者简介: 王彦峰, 男, 1983 年生, 高级工程师, 西北有色金属研究院腐蚀与防护研究所, 陕西 西安 710016, 电话: 029-86283410, E-mail: yfwang420@163.com 